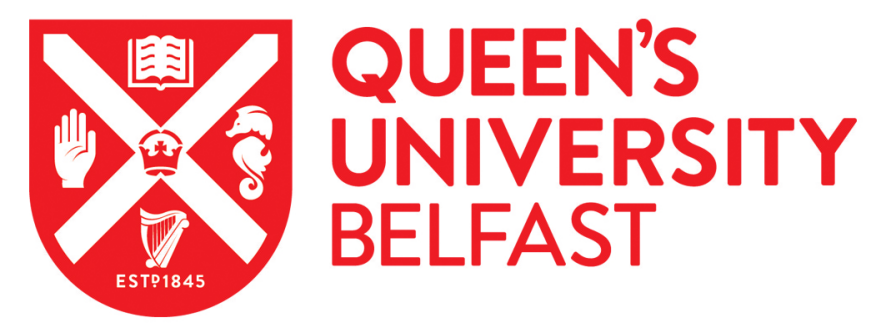

\title{
Variations in serum vascular endothelial growth factor binding profiles and the development of ovarian hyperstimulation syndrome.
}

McElhinney, B., Ardill, J., Caldwell, C., Lloyd, F., \& McClure, N. (2002). Variations in serum vascular endothelial growth factor binding profiles and the development of ovarian hyperstimulation syndrome. Fertility and Sterility, 78(2)(2), 286-290.

Published in:

Fertility and Sterility

Queen's University Belfast - Research Portal:

Link to publication record in Queen's University Belfast Research Portal

\section{General rights}

Copyright for the publications made accessible via the Queen's University Belfast Research Portal is retained by the author(s) and / or other copyright owners and it is a condition of accessing these publications that users recognise and abide by the legal requirements associated with these rights.

Take down policy

The Research Portal is Queen's institutional repository that provides access to Queen's research output. Every effort has been made to ensure that content in the Research Portal does not infringe any person's rights, or applicable UK laws. If you discover content in the Research Portal that you believe breaches copyright or violates any law, please contact openaccess@qub.ac.uk. 


\title{
Variations in serum vascular endothelial growth factor binding profiles and the development of ovarian hyperstimulation syndrome
}

\author{
Bernie McElhinney, M.B., ${ }^{\mathrm{a}, \mathrm{b}}$ Joy Ardill, Ph.D., ${ }^{\mathrm{c}}$ Carolyn Caldwell, ${ }^{\mathrm{c}}$ Freddie Lloyd, ${ }^{\mathrm{d}}$ and \\ Neil McClure, M.D. ${ }^{\mathrm{a}, \mathrm{b}}$ \\ School of Medicine, Queen's University, and the Regional Fertility Centre, Royal Groups of Hospitals' Trust, \\ Belfast, Northern Ireland
}

Received July 10, 2001; revised and accepted February 27, 2002. Presented in part at the British Fertility Society Annual Meeting, Belfast, Northern Ireland, April 2001 and in full at the

International Federation of Fertility Societies Meeting, Melbourne, Australia, November 2001.

Reprint requests: Bernie McElhinney, M.B., School of Medicine, Obstetrics and Gynaecology, Queen's University, Belfast, Institute of Clinical Science, Grosvenor Road, Belfast BT12 6BJ, Northern Ireland (FAX: 028 90328247; Email:

b.mcelhinney@qub.ac.uk).

a School of Medicine, Obstetrics and Gynaecology, Queen's University.

${ }^{\mathrm{b}}$ The Regional Fertility Centre, Royal Group of Hospitals' Trust.

'School of Medicine, Queen's University.

d The Protein Laboratory, Belfast City Hospital.

$0015-0282 / 02 / \$ 22.00$ PII S0015-0282(02)03209-0

Objective: To compare the ability of serum to sequester vascular endothelial growth factor (VEGF) among patients who did and did not develop ovarian hyperstimulation syndrome (OHSS).

Design: Prospective, observational study.

Setting: A regional fertility centre with a commitment to research.

Patient(s): Five patients undergoing controlled ovarian hyperstimulation as part of an in vitro fertilization cycle who developed severe OHSS, and five controls.

Intervention(s): Serum, collected at the time of oocyte retrieval, was incubated with radioactive VEGF $\left({ }^{125} \mathrm{I}_{-} \mathrm{VEGF}_{165}\right)$ for 2 hours before being passed down a sephadex G-150 gel filtration column. The fractional radioactive profile was then determined.

Main Outcome Measure(s): The distribution of radioactive VEGF across the various fractions was measured in serum samples obtained from the two groups.

Result(s): The ${ }^{125} \mathrm{I}_{-V_{E G F}}$ applied to the column eluted in two peaks centered on fractions $18 \pm 2$ and $39 \pm 2$. The molecular weight in the first peak was $>300,000 \mathrm{kDa}$ and represented "bound" VEGF; the second peak represented "unbound" VEGF. In the OHSS group, there was statistically significantly less radioactivity in the first peak than in the no-OHSS group.

Conclusion(s): Patients who do not develop OHSS appear to have a high-molecular-weight protein that binds VEGF to a greater degree than occurs in patients who develop OHSS. (Fertil Steril ${ }^{\circledR} 2002 ; 78: 286-90$. (C2002 by American Society for Reproductive Medicine.)

Key Words: OHSS, VEGF, column chromatography, binding protein, inactivating protein

Ovarian hyperstimulation syndrome (OHSS) is the most serious complication of controlled ovarian hyperstimulation $(\mathrm{COH})$. In its most severe form, which occurs in $0.3 \%$ to $5.0 \%$ of cycles (1), it is associated with significant morbidity and can be life threatening. The pathophysiology is unclear and specific therapeutic management is not available. The syndrome is associated with ovarian enlargement and an increase in capillary permeability (2), which leads to an extensive, predominantly intra-abdominal accumulation of fluid. The resultant depletion of intravascular fluid volume leads, in turn, to secondary hemodynamic consequences, particularly increased coagulation and prerenal failure. The effect of excessive gonad- otropins on ovarian tissue accounts for the ovarian enlargement, whereas the cause of the increased capillary permeability and subsequent third space accumulation is unknown.

Although the pathophysiology of OHSS is unknown, it seems probable that the release of a vasoactive substance secreted by the ovaries under human chorionic gonadotropin (hCG) stimulation plays a key role in triggering this syndrome $(2,3)$. Several substances have been proposed as the intermediary responsible for the increase in capillary permeability. However, exaggerated folliculogenesis (4) and the interaction between the immune and reproductive systems (5) are the pathogenetic forerunners. 
Cascade of events leading to the development of OHSS.

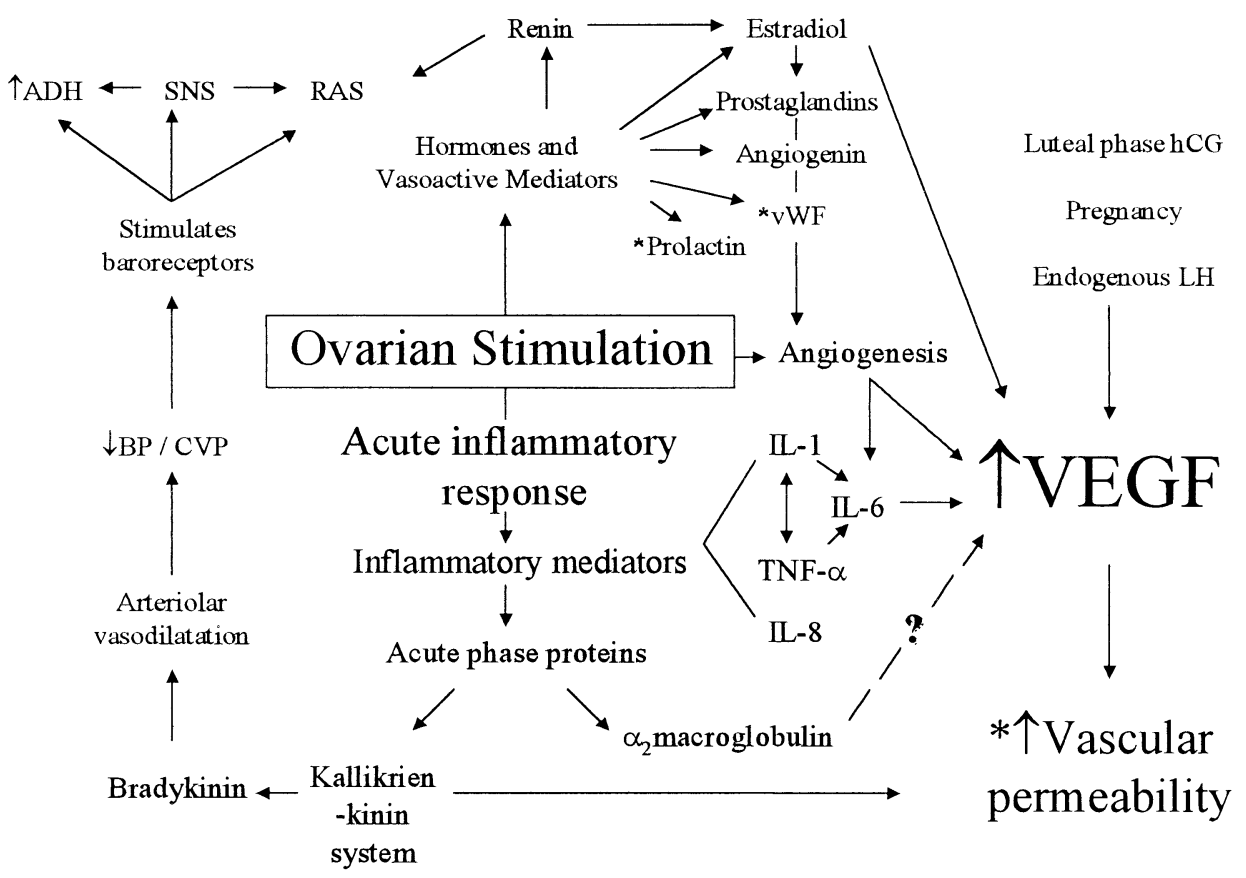

McElhinney. Serum VEGF profiles and OHSS. Fertil Steril 2002.

Physiological angiogenesis is infrequent; when it does occur, it seems to be restricted to females (6). Angiogenesis is an essential component of both follicular and luteal phases of the ovarian cycle (7) but is particularly aggressive in early luteogenesis. Vascular endothelial growth factor (VEGF) has emerged as one of the most important inducers of angiogenesis in the ovary. During follicular growth, the dominant follicle develops a complex vascular network within the thecal layer; VEGF-dependent angiogenesis is essential for corpus luteum development (8). Phillips et al. (9) described a temporal and spatial relationship between VEGF mRNA expression and physiological proliferation of blood vessels in the ovarian corpus luteum.

Studies on VEGF in OHSS patients have shown that it may be responsible for the increase in vascular permeability seen in this syndrome (10). Serum VEGF levels were significantly higher on day 14 after hCG administration in a group who developed severe OHSS, compared with those who did not (11). Similarly, high VEGF plasma levels have been demonstrated in patients with severe OHSS, which dropped significantly with clinical improvement (12). Furthermore, the kinetics of VEGF in the plasma of patients who developed OHSS was closely correlated with the clinical course of the syndrome and with certain biological characteristics. McClure et al. (10) found that VEGF was the major capillary permeability factor in OHSS ascites, as addition of specific antibodies against VEGF neutralized 70\% of capillary permeability activity.

There would appear to be no doubt that VEGF is an essential component of the physiological angiogenesis that accompanies follicular growth. In contrast to the development of one follicle in a natural cycle, multiple follicles are associated with an excess of VEGF, which can overspill the ovarian capillary bed and exert its effects in the peritoneal cavity. In addition to inducing angiogenesis and producing proliferation of endothelial cells during corpus luteum growth, VEGF induces vascular permeability. Endothelial cell permeability induced by the follicular fluid of patients undergoing assisted reproduction therapy was highly correlated with oocyte number. This effect was almost completely reversed by the addition of anti-VEGF antibody (13). Previously, Goldsman et al. (2) had reported an augmentation in the permeability rate of both follicular fluid and peritoneal fluid from patients undergoing $\mathrm{COH}$ who responded with an increasing number of oocytes compared with controls. Therefore, it is likely that VEGF is the follicular fluid factor responsible for the increased vascular permeability, and hence morbidity, in OHSS (Fig. 1).

Only a minority of patients with ovarian hyperstimula- 
tion, however, go on to develop the syndrome. It is possible that some patients can deal endogenously with the excess levels of VEGF better than others. Some of the variations in symptoms attributable to VEGF levels between women may be explained by variations in the level of free and sequestered VEGF.

The objective of this study was to determine if the serum of patients who developed OHSS differed in its ability to bind VEGF in vitro when compared with the serum of patients who did not develop OHSS, despite processing large numbers of oocytes for oocyte retrieval.

\section{MATERIALS AND METHODS}

\section{Patient Selection and Study Design}

This study was performed between August 1998 to July 2000. Serum was collected prospectively from 218 women who were undergoing in vitro fertilization (IVF) at the time of oocyte retrieval. Subsequently five women $(2 \%)$ were identified who developed severe OHSS (14) (Group 1). Five control patients who did not develop OHSS were identified from the cohort tested (Group 2). All of the women had more than 15 oocytes and were matched for age and diagnosis.

In addition, a chart review identified two women who had been hyperstimulated during a previous cycle of IVF, one of whom had developed critical OHSS and one who had remained asymptomatic. Consent was obtained and serum was collected on three occasions during a natural cycle from both women (day 1 to 5, periovulatory and midluteal).

All clinical procedures were performed at the Regional Fertility Centre Royal Maternity Hospital, Belfast. Ethical approval for the study was obtained from the Queen's University Belfast research ethics committee.

\section{Assisted Reproduction Stimulation Procedure}

All patients underwent a standard stimulation protocol with pituitary down-regulation by gonadotrophin-releasing hormone agonist analogue (GnRH-a) (Synarel, Searle, High Wycombe, UK) commenced in the midluteal phase and administered nasally until the ovulatory hCG injection. Ovulation induction was with human menopausal gonadotrophin (hMG) (Menogon, Ferring, Langley, UK) or recombinant follicle stimulating hormone ( $\mathrm{rFSH}$ ) (Gonal F, Serono Pharmaceuticals, Feltham, UK; or Puregon, Organon Laboratories Ltd., Cambridge, UK) in a high, standard, or low dose regimen.

The women were scanned on day 11 of stimulation to determine the degree of ovarian response. Those with fewer than four follicles $>18 \mathrm{~mm}$ in diameter had their cycle abandoned. The remainder received an hCG (Profasi, Serono) injection of 10,000 IU to induce final oocyte maturation. At 34 to 36 hours after hCG administration, all ovarian follicles were aspirated transvaginally under ultrasound control. The women received Rapifen (Janssen-Cilag, High-
Wycombe, UK) intravenously as necessary for pain relief. Immediately before commencing oocyte retrieval, a sample of peripheral blood was taken. The blood was allowed to clot, then was refrigerated and centrifuged before the serum was withdrawn. The serum samples were stored at $-70^{\circ} \mathrm{C}$ until required for analysis. Women thought to be at significant risk of OHSS (guideline: total oocyte number $>15$ ) were offered the option of embryo freezing rather than fresh embryo transfer.

\section{Column Chromatography}

Serum samples were applied sequentially to a sephadex G-150 gel filtration column measuring $1.0 \times 60 \mathrm{~cm}$. The column was eluted with phosphate buffer, $0.04 \mathrm{M}, \mathrm{pH} 7.4$, which contained bovine serum albumin (BSA, 0.1\% Sigma RIA grade). A flow rate of $4 \mathrm{~mL} /$ hour was used. Chromatography was performed at $4^{\circ} \mathrm{C}$ and $500 \mu \mathrm{L}$ fractions were collected.

Serum (175 $\mu \mathrm{L})$ from five women who developed severe OHSS and five case-matched controls was incubated with ${ }^{125} \mathrm{I}_{-\mathrm{VEGF}_{165}}$ (Amersham Pharmacia Biotech, UK Ltd.) (25 $\mu \mathrm{L})$ for 2 hours at room temperature. The samples $(200 \mu \mathrm{L})$ were applied to the column in turn. Fraction radioactivity was analysed by a gamma counter (Wallac 1277 Gammamaster, automatic gamma counter).

The ${ }^{125} \mathrm{I} \mathrm{VEGF}_{165}$ applied to the column eluted in two peaks centered on fractions $18 \pm 2$ and $39 \pm 2$. The first peak was a high-molecular-weight compound $(>300 \mathrm{kDa})$ representing "bound" ${ }^{125} \mathrm{I}-\mathrm{VEGF}_{165}$. The second peak was understood to be unbound ${ }^{125}{\mathrm{I}-\mathrm{VEGF}_{165}}$ because the elution pattern was identical to that of neat ${ }^{125} \mathrm{I}_{-} \mathrm{VEGF}_{165}$. The percentage of ${ }^{125}{\mathrm{I}-\mathrm{VEGF}_{165}}_{16}$ bound in each group was calculated and compared.

In addition, during a natural cycle, the serum from the woman who had 17 oocytes collected during a cycle of IVF and developed critical OHSS was subjected to analysis, as was the serum from the woman who had 41 oocytes collected and remained asymptomatic. In both cases the periovulatory blood sample was prepared and subjected to analysis by column chromatography. Recovery from the column was $>90 \%$.

\section{Statistical Analysis}

All data are presented as median (interquartile range). Due to the non-Gaussian distribution of the data, differences between the two groups were assessed by the Mann-Whitney $U$-test. All analyses were performed using the Statistica package (Statsoft Version 5.1, Hamburg, Germany). The level of significance was set at $P \leq .05$.

\section{RESULTS}

There was no statistically significant difference between the two groups with regards to age, duration of infertility, dose of gonadotropins, and number of oocytes collected. 
Comparison between the characteristics of the group who developed OHSS and the group who remained symptom free.

\begin{tabular}{lccc}
\hline Patient characteristics & OHSS cases & Control cases & $P$ value \\
\hline Number of cases & 5 & 5 & \\
Age (years) & $32(30-40)$ & $30(27-32)$ & .2 \\
Duration of infertility (years) & $4(2-5)$ & $4(4-5)$ & .91 \\
Dose of gonadotropins & $1860(1760-1960)$ & $1830(1830-2130)$ & .67 \\
Number of oocytes retrieved & $20(19-35)$ & $22(18-37)$ & .68 \\
Number of successful embryo transfers & 1 & 1 & $19.2(14-20)$ \\
$\%$ VEGF bound & $10(8.6-13)$ & & $<.05$ \\
\hline
\end{tabular}

Values are medians (interquartile range). Significance $P<.05$, Mann-Whitney $U$-test.

McElhinney. Serum VEGF profiles and OHSS. Fertil Steril 2002.

In all of the column chromatography studies on serum from cases with or without OHSS there were two peaks of radioactivity centered on fractions $18 \pm 2$ and $39 \pm 2$, representing "bound" and "unbound" VEGF. There was statistically significantly less ${ }^{125} \mathrm{I}-V E G F_{165}$ bound in the first peak in the group who developed OHSS (10 [8.6 to 13] vs. 19.2 [14 to 20]; $P<.05)$ than in the group who did not develop OHSS (Table 1).

In the "natural cycle" column chromatography study, the serum from the woman who produced 41 oocytes but remained well bound significantly more of the ${ }^{125}$ I-VEGF $_{165}$ $(37.4 \%$ vs. $13.75 \%)$ than that of the woman with a history of 17 oocytes and critical OHSS. This difference was statistically significant $(P<.001)$, Mann-Whitney $U$-test (Fig. 2$)$.

\section{DISCUSSION}

This is the first time that it has been suggested that some patients are inherently protected from developing OHSS.

\section{FIGURE 2}

Column chromatography of "natural cycle" serum in two women with and without a history of OHSS in a previous cycle of $\mathrm{COH}$ for IVF. Solid line $=41$ oocytes, no-OHSS. Dotted line $=17$ oocytes, critical OHSS.

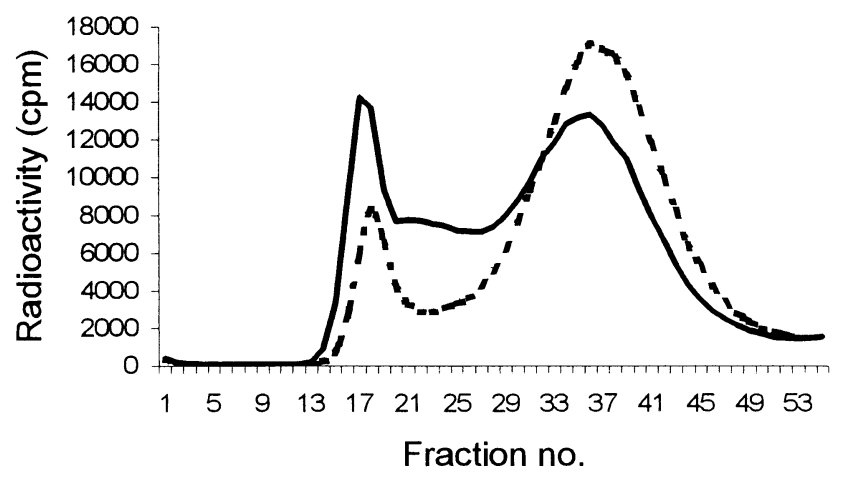

McElhinney. Serum VEGF profiles and OHSS. Fertil Steril 2002.
The putative factor would appear to be a high-molecularweight serum protein. This is particularly relevant as it may offer the possibility of supplementation of the factor as a therapy for OHSS.

With rare exceptions, OHSS is an iatrogenic condition that occurs in otherwise healthy young women. The pathophysiology is still unclear. Further, there are no specific therapeutic measures. Therefore, the most effective management is its accurate prediction and active prevention. Surprisingly, the introduction of estradiol measurement and ultrasonography has proved to be of limited value in this respect. This lends support to the concept that the degree of ovarian stimulation may not be the only factor in the pathogenesis of the condition.

In a natural menstrual cycle, ovarian angiogenesis is normally restricted to a single follicle and OHSS does not occur. In cases of ovarian hyperstimulation, multiple follicles are associated with supraphysiologic angiogenic activity. The substantial increase in the number of corpora lutea seen in ovarian hyperstimulation compared with that of a natural cycle may result in unnaturally high levels of circulating VEGF. Accumulated data would suggest that the possible mechanism of increased capillary permeability found in OHSS might be due to the systemic effect of VEGF and not its origin in the ovary (15). Therefore, VEGF may overspill the ovarian capillary bed and exert its effects systemically.

The biological relationship between VEGF and OHSS has been well established. Indeed, the central role of VEGF as the mediator involved in OHSS pathogenesis is not in dispute. However, other factors must be involved. If "oocyte number" correlates with VEGF and VEGF is the agent responsible for the development of OHSS, why is it that only a minority of patients with ovarian hyperstimulation develop the syndrome?

Several studies have demonstrated that, although VEGF levels are elevated in patients with hyperstimulated ovaries (16), there is no statistically significant difference between those with hyperstimulated ovaries who subsequently de- 
velop OHSS and those who do not (17-20). Other factors must interfere with the systemic effects of VEGF. Ludwig et al. (21) demonstrated a 100-fold higher concentration of total circulating VEGF than the concentration of free VEGF. Furthermore, patients who developed OHSS had significantly more free VEGF although no such difference existed with respect to total circulating VEGF. This work is in agreement with our hypothesis that patients who are protected from the development of OHSS are able to sequester more of the free VEGF.

The prime target cells for VEGF are the endothelial cells (22). Therefore, a binding protein for VEGF may be present in patients' serum in differing amounts. The binding protein acts as a removing and inactivating protein, and the relationship between the level of the binding protein and free VEGF determines whether a patient develops OHSS.

Binding proteins for growth factors fall into two categories: [1] membrane-bound high affinity binding proteins, or receptors, and [2] soluble binding proteins secreted from cells. Soluble binding proteins may act to inactivate the biological activity of the protein, in this case VEGF. These results would be in keeping with the presence of a binding protein in patients' serum that inactivates the VEGF, variations in the level offering different degrees of protection.

This work is novel in that it suggests that it is how individuals deal with the VEGF that determines whether they develop the syndrome. The serum from the no-OHSS group of patients sequestered significantly more of the radioactive VEGF than did the OHSS group.

Despite the small numbers included in this study, the results strongly support the concept that patients' serum may contain a VEGF removing and inactivating protein whose activity varies between individuals. Some of the variation in symptoms attributable to VEGF levels between women may be explained by variations in the levels of free and bound VEGF receptor proteins. Apparently, to date, no studies exploring these relationships have been published. Work is ongoing to determine the nature of this VEGF-binding protein.

\section{References}

1. Schenker JG, Weinstein D. Ovarian hyperstimulation syndrome: a current survey. Fertil Steril 1978;30:255-68.

2. Goldsman MP, Pedram A, Dominguez C, Ciuffardi I, Levin E, Asch $\mathrm{RH}$. Increased capillary permeability induced by human follicular fluid: a hypothesis for an ovarian origin of the hyperstimulation syndrome Fertil Steril 1995;63:268-72.

3. Tsirigotis M, Craft I. Ovarian hyperstimulation syndrome (OHSS): how much do we really know about it? Eur J Obstet Gynecol 1994;55: $151-5$.

4. Navot D, Relou A, Birkenfeld A, Rabinowitz T, Brzezinski A, Margalioth EJ. Risk factors and prognostic variables in the ovarian hyperstimulation syndrome. Am J Obstet Gynecol 1988;159:210-5.

5. Orvieto R, Ben-Rafael Z. Ovarian hyperstimulation syndrome: a new insight into an old enigma. J Soc Gynecol Invest 1998;5:110-3.

6. Folkman J, Klagsbrun M Angiogenic factors. Science 1987;235:442-7.

7. Ratcliffe KE, Anthony FW, Richardson MC, Stones RW. Morphology and functional characteristics of human ovarian microvascular endothelium. Hum Reprod 1999;14:1549-54.

8. Ferrara N, Chen H, Davis-Smyth T, Gerber HP, Nguyen TN, Peers D, et al. Vascular endothelial growth factor is essential for corpus luteum angiogenesis Nat Med 1998;4:336-40.

9. Phillips HS, Hains J, Leung DW, Ferrara N. Vascular endothelial growth factor is expressed in rat corpus luteum. Endocrinology 1990; 127:965-7.

10. McClure N, Healy DL, Rogers PA. Vascular endothelial growth factor as a capillary permeability factor in ovarian hyperstimulation syndrome. Lancet 1994;344:235-69.

11. Krasnow J, Berga S, Guzick D, Zeleznik A, Yeo K-T. Vascular permeability factor and vascular endothelial growth factor in ovarian hyperstimulation syndrome: a preliminary report. Fertil Steril 1996;65: $552-5$.

12. Abramov Y, Barak V, Nisman B, Schenker J. Vascular endothelial growth factor plasma levels correlate to the clinical picture in severe ovarian hyperstimulation syndrome. Fertil Steril 1997;67:261-5.

13. Levin ER, Rosen GF, Cassidenti DL, Yee B, Meldrum D, Wisot A, Pedram A. Role of vascular endothelial growth factor in ovarian hyperstimulation syndrome. J Clin Invest 1998;102:1978-85.

14. Golan A, Ron-El R, Herman A, Soffer Y, Weinraub Z, Caspi E. Ovarian hyperstimulation syndrome: an update review. Obstet Gynecol Surv 1989;44:430-40.

15. Yarali H, Fleige-Zahradka BG, Ho Yuen B, McComb F. The ascites in the ovarian hyperstimulation syndrome does not originate from the ovary. Fertil Steril 1993:59:657-61.

16. Agrawal R, Tan SL, Wild S, Sladkevicius P, Engmann L, Payne N, et al. Serum vascular endothelial growth factor concentrations in vitro fertilisation cycles predict the risk of ovarian hyperstimulation syndrome Fertil Steril 1999:71:287-93.

17. Enskog A, Nilsson L, Brannstrom M. Plasma levels of free vascular endothelial growth factor165 (VEGF165) are not elevated during gonadotrophin stimulation in in vitro fertilization (IVF) patients developing ovarian hyperstimulation syndrome (OHSS): results of a prospective cohort study with matched controls. Eur J Obstet Gynecol Reprod Biol 2001;96:196-201.

18. Mathur R, Hayman G, Bansal A, Jenkins J. Serum vascular endothelial cell growth factor (VEGF) levels in highly responsive women are poorly predictive of subsequent ovarian hyperstimulation syndrome (OHSS). In: Programme and Abstract Book of the British Fertility Society's Annual Meeting. Belfast 2001.

19. Chen C-D, Chen H-F, Lu H-F, Chen S-U, Ho H-N, Yang Y-S. Value of serum and follicular fluid cytokine profile in the prediction of moderate to severe ovarian hyperstimulation syndrome. Hum Reprod 2000;15:1037-42.

20. Geva E, Amit A, Lessing JB, Lerner-Geva L, Daniel Y, Yovel I et al. Follicular fluid levels of vascular endothelial growth factor. Are they predictive markers for ovarian hyperstimulation syndrome? J Reprod Med 1999;44:91-6.

21. Ludwig M, Jelkmann W, Bauer O, Diedrich K. Prediction of severe ovarian hyperstimulation syndrome by free serum vascular endothelial growth factor concentration on the day of human chorionic gonadotrophin administration. Hum Reprod 1999;14:2437-41.

22. Ferrara N, Davis-Smyth T. The biology of vascular endothelial growth factor. Endocr Rev 1997;18:4-25. 